\title{
Higher immunoglobulin production in conjugated linoleic acid-supplemented rats during gestation and suckling
}

\author{
Carolina Ramírez-Santana ${ }^{1,2}$, Francisco J. Pérez-Cano ${ }^{1,2} *$, Cristina Castellote ${ }^{1,2,3}$, Margarida Castell ${ }^{1,2}$, \\ Montserrat Rivero ${ }^{4}$, María Rodríguez-Palmero ${ }^{4}$ and Àngels Franch ${ }^{1,2,3}$ \\ ${ }^{1}$ Department of Physiology, Faculty of Pharmacy, University of Barcelona, Av. Joan XXIII s/n, E-08028 Barcelona, Spain \\ ${ }^{2}$ Institut de Recerca en Nutrició $i$ Seguretat Alimentaria (INSA-UB), Barcelona, Spain \\ ${ }^{3}$ CIBER Epidemiología y Salud Pública (CIBERESP), Barcelona, Spain \\ ${ }^{4}$ Ordesa Group, Research Department, Scientific Park of Barcelona, Barcelona, Spain
}

(Received 24 September 2008 - Revised 9 February 2009 - Accepted 10 February 2009 - First published online 2 April 2009)

Conjugated linoleic acid (CLA) has been reported to exert beneficial physiological effects on body composition and the immune system. However, little information is available on the influence of CLA on immune function during early life periods. The present study evaluates the effect of feeding an 80:20 mixture of cis-9, trans-11- and trans-10, cis-12-CLA isomers during gestation and suckling on the systemic immune response of weaned Wistar rats. Pups received dietary CLA from dams through the placental barrier and during suckling by breast milk (group A) or by oral administration (group B). Pups from group C only received CLA during suckling by oral administration. Group D constituted the reference group. Milk from dams fed the CLA diet had a high content of CLA and higher IgA and IgG concentrations than rats fed the standard diet. The plasma of pups from groups A, B and C showed six, twelve and nine times higher content of the cis-9, trans-11-CLA isomer than that of the group D pups. Rats from group A exhibited higher serum IgG concentrations than rats from the rest of the groups (22.14 (SEM 2.14$) v$. about $5 \mathrm{mg} / \mathrm{ml} ; P<0.05)$, whereas rats from groups A and B showed approximately 2-fold higher splenocyte IgM production than rats from groups C and D. However, CLA supplementation did not influence significantly the splenocyte proliferative response or cytokine secretion. Supplementation during gestation and suckling with an 80:20 cis-9, trans-11-trans-10, cis-12 CLA mix enhances the production of the main in vivo and in vitro Ig isotypes in Wistar rats.

Conjugated linoleic acid: Rats: Gestation: Suckling: Immune response

The systemic and mucosal immune systems are continuously in development, and their function is highly influenced by maternal, environmental, dietary and behavioural factors ${ }^{(1-3)}$. In rats and man, before birth, IgG crosses the placenta and reaches the fetus; thereafter, milk constitutes the communication route between the maternal and infant immune systems. It represents an active mechanism directing and educating the immune system, metabolism and gut microflora within the infant, while conferring multiple means of protection from pathogens $^{(4,5)}$. Breast milk has Ig and many other bioactive molecules, such as growth factors, cytokines, nucleotides, cellular components and lipids, which promote maturation of the developing immune system ${ }^{(5-7)}$.

It has been suggested that PUFA, specifically DHA and arachidonic acid, which constitute a relatively low fraction of the total fatty acids in human breast milk, participate in neonate immune development ${ }^{(8)}$. In parallel, conjugated linoleic acid (CLA), a PUFA found in breast milk, has been also suggested to contribute to immune development ${ }^{(9-12)}$. The predominant CLA isomer in dairy products is cis-9, trans-11 (c9,t11)-CLA, also called rumenic acid, which ranges in human milk from 83 to $100 \%$ of total $\mathrm{CLA}^{(9,11)}$. The trans-10, cis-12 $(t 10, c 12)-C L A$ isomer is also found in dairy products, but in lower proportions. In human milk, this isomer is in lower amounts than rumenic acid ${ }^{(11,13)}$. Even very low doses of the $t 10, c 12$-CLA isomer seem to have large biological effects $^{(14)}$.

CLA has been reported to exert beneficial physiological effects on the development of cancer ${ }^{(15)}$, atherosclerosis ${ }^{(16)}$, diabetes $^{(17)}$, and on body composition ${ }^{(18)}$. The immunomodulatory properties of CLA in both rodents and human subjects show controversial results ranging from stimulation to inhibition $^{(19-22)}$. These discrepancies are mainly due to the different mixtures of CLA isomers used in the studies, since each isomer has specific biological effects. The $t 10, c 12-\mathrm{CLA}$ isomer is responsible for body fat reduction ${ }^{(23-25)}$, although both CLA isomers have shown immunomodulatory effects $^{(19-22)}$.

Although many studies have been carried out with CLA isomer mixtures, most of them have used 50:50 mixtures of the $c 9, t 11$ and $t 10, c 12$ isomers and have been carried out in animals of at least 3 weeks old. Based on the predominance 
of the $c 9, t 11$-CLA isomer in breast milk and that CLA intake during developmental phases might have effects later in life ${ }^{(26,27)}$, we hypothesised that CLA would be transferred from dams to pups and exert immune-enhancing effects. Thus, the aim of the present immunonutrition study was to investigate the effects of supplementing Wistar rats from gestation to the end of suckling with an 80:20 isomer mixture of $c 9, t 11$ - and $t 10, c 12$-CLA on the systemic immune response in Wistar rats. We quantified CLA transfer to pups, serum and milk Ig concentrations, in vitro splenocyte Ig production and spleen cell proliferation and cytokine secretion ability as biomarkers of immune development.

\section{Materials and methods}

\section{Animals}

Pregnant Wistar rats at $7 \mathrm{~d}$ gestation were obtained from Harlan (Barcelona, Spain). The animals were housed in individual cages under controlled temperature and humidity conditions in a $12 \mathrm{~h}$ light $-12 \mathrm{~h}$ dark cycle, and had access to food and water ad libitum. The rats were monitored daily and allowed to deliver at term. The day of birth was registered as day 1 of life. Litters were unified to ten pups per lactating dam; pups had free access to the nipples and rat diet. Animals were daily identified and weighed, and handling was done in the same time range to avoid the influence of biological rhythms. Body weight and body length (nose-anus length) were used to determine the following morphometrical parameters: BMI, calculated as body weight $/$ length ${ }^{2}\left(\mathrm{~g} / \mathrm{cm}^{2}\right)$; the Lee index, calculated as ${ }^{3} \sqrt{ }$ weight/length $(\mathrm{g} / \mathrm{cm})$, as markers of obesity in rats and other mammals ${ }^{(28)}$.

At the day of weaning (day 21), rats were anaesthetised with ketamine $(90 \mathrm{mg} / \mathrm{kg}$ rat weight) and xylazine $(10 \mathrm{mg} / \mathrm{kg}$ rat weight) to obtain spleen and blood for serum and plasma samples, which were immediately frozen at $-80^{\circ} \mathrm{C}$ until processing. Studies were performed in accordance with the institutional guidelines for the care and use of laboratory animals established by the Ethical Committee for Animal Experimentation of the University of Barcelona and approved by the Catalonian Government (CEEA 303/05, UB/DMA 3242).

Pregnant rats were randomly assigned to one of the following four dietary groups, according to the total period of CLA supplementation and administration route used in the pups (Fig. 1):

Group A. Group A were pups from dams fed a $1 \%$ CLA diet (see below) during the last 2 weeks of gestation and throughout the suckling period. During suckling, the pups received CLA through the dams' milk. The total period of supplementation was 5 weeks.

Group B. Group B were pups from dams fed during gestation the $1 \%$ CLA diet and during suckling a standard diet $\left(\mathrm{AIN}-93 \mathrm{G}^{(29)}\right)$. The pups were CLA supplemented daily during suckling by oral administration. The total period of supplementation was 5 weeks.

Group C. Group C were pups from dams fed the standard diet during gestation and suckling. The pups received CLA by daily oral administration throughout the suckling period. The total period of supplementation was 3 weeks.

Group D. Group D were pups from dams fed the standard diet throughout the study. These animals constitute the reference diet group. The total period of supplementation was 0 weeks.

\section{Diets}

The standard diet corresponded to the AIN-93G formulation $^{(29)}$, containing $7 \%$ soyabean oil. The $1 \%$ CLA diet was obtained from modified standard flour (AIN-513; Harlan) containing $10 \mathrm{~g} \mathrm{CLA} / \mathrm{kg}$ (Table 1). Thus, the supplemented diet contained $6 \%$ soyabean oil plus $1 \%$ CLA oil. The CLA isomer mixture used was approximately $80 \%$ $c 9, t 11$ and $20 \% t 10, c 12$ from the total CLA isomers in oil. The CLA mixture had $0.69 \%$ NEFA as oleic acid, a peroxide value of $0.2 \mathrm{mEq} / \mathrm{kg}, 5.6 \%$ SFA and less than $5 \%$ of minor CLA isomers. CLA oil was kindly supplied by Loders Croklaan (Lipid Nutrition, Wormerveer, The Netherlands).

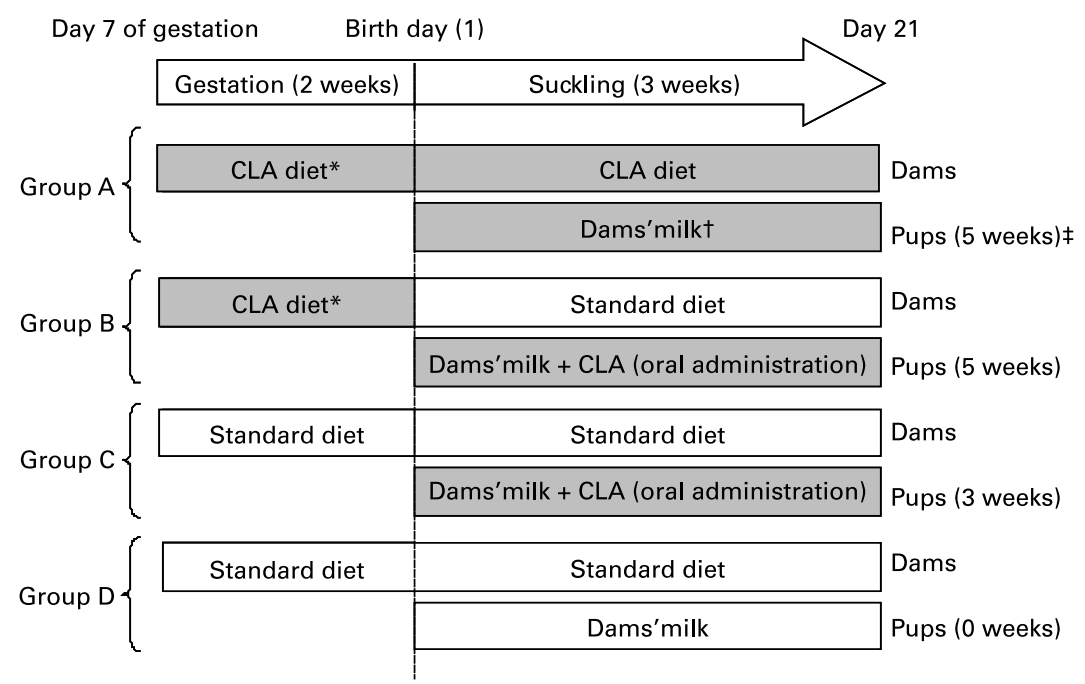

Fig. 1. Diagram of the experimental design beginning on day 7 of gestation until day 21 of suckling. ${ }^{*}$ Conjugated linoleic acid (CLA) arrives at the fetus by transplacental transfer. †CLA arrives at pups through the milk of dams. $\ddagger$ Indicates total period of CLA supplementation from gestation until the end of suckling. ( $\square$ ), CLA-supplemented animals; ( $\square$ ), non-supplemented animals. 
Table 1. Composition of experimental dams' diets ( $\mathrm{g} / \mathrm{kg}$ diet)

\begin{tabular}{|c|c|c|}
\hline Ingredient & AIN-93G* & $1 \%$ CLA \\
\hline Total energy $(\mathrm{kJ})$ & 15767 & 15763 \\
\hline Percentage energy as fat & $16 \cdot 7$ & $16 \cdot 7$ \\
\hline Percentage energy as CLA oil & - & $2 \cdot 39$ \\
\hline Percentage energy as soyabean oil & $16 \cdot 7$ & $14 \cdot 3$ \\
\hline Casein & 200 & $199 \cdot 9$ \\
\hline L-Cysteine & 3 & 2.9 \\
\hline Maize starch & $397 \cdot 5$ & 397.5 \\
\hline Maltodextrin & 132 & 131.9 \\
\hline Sucrose & 100 & 99.9 \\
\hline Cellulose & 50 & $49 \cdot 9$ \\
\hline Mineral mix $†$ & 35 & 34.9 \\
\hline Vitamin mix $\ddagger$ & 10 & 9.9 \\
\hline Choline bitartrate & $2 \cdot 5$ & 2.5 \\
\hline Tert-butylhydroquinone§ & 0.014 & 0.014 \\
\hline Soyabean oil & 70 & 59.9 \\
\hline $16: 0$ & $7 \cdot 7$ & $6 \cdot 7$ \\
\hline $18: 0$ & $2 \cdot 8$ & $2 \cdot 4$ \\
\hline $18: 1$ & $16 \cdot 4$ & $14 \cdot 2$ \\
\hline $18: 2$ & $37 \cdot 2$ & $32 \cdot 2$ \\
\hline $18: 3$ & $5 \cdot 6$ & $4 \cdot 8$ \\
\hline Cis-9, trans-11-CLA\| & - & $7 \cdot 2$ \\
\hline Trans-10, cis-12-CLA\| & - & $1 \cdot 8$ \\
\hline
\end{tabular}

CLA, conjugated linoleic acid.

* The diet was prepared according to AIN guidelines ${ }^{(29)}$

† Supplied (per $\mathrm{kg}$ diet): $357 \mathrm{~g}$ calcium carbonate, $196 \mathrm{~g}$ potassium phosphate monobasic, $70.78 \mathrm{~g}$ potassium citrate, $74 \mathrm{~g}$ sodium chloride, $46.6 \mathrm{~g}$ potassium sulfate, $24.3 \mathrm{~g}$ magnesium oxide, $6.06 \mathrm{~g}$ ferric citrate, $1.65 \mathrm{~g}$ zinc carbonate, $0.63 \mathrm{~g}$ manganous carbonate, $0.31 \mathrm{~g}$ cupric carbonate, $0.01 \mathrm{~g}$ potassium iodate, $0.01025 \mathrm{~g}$ sodium selenate, $0.00795 \mathrm{~g}$ ammonium paramolybdate, $1.45 \mathrm{~g}$ sodium meta-silicate, $0.275 \mathrm{~g}$ chromium potassium sulfate, $0.0174 \mathrm{~g}$ lithium chloride, $0.0815 \mathrm{~g}$ boric acid, 0.0635 sodium fluoride, $0.0318 \mathrm{~g}$ nickel carbonate hydroxide, tetrahydrate, $0.0066 \mathrm{~g}$ ammonium vanadate and $220.716 \mathrm{~g}$ sucrose.

$\ddagger$ Supplied (per kg diet): $3 \mathrm{~g}$ nicotinic acid, $1.6 \mathrm{~g}$ calcium pantothenate, $0.7 \mathrm{~g}$ pyridoxine $\mathrm{HCl}, 0.6 \mathrm{~g}$ thiamin $\mathrm{HCl}, 0.6 \mathrm{~g}$ riboflavin, $0.2 \mathrm{~g}$ folic acid, $0.02 \mathrm{~g}$ D-biotin $2.5 \mathrm{~g}$ vitamin $\mathrm{B}_{12}(0.1 \%$ in mannitol), $15 \mathrm{~g} \mathrm{DL}-\alpha$ tocopheryl acetate $(500 \mathrm{IU} / \mathrm{g})$ $0.8 \mathrm{~g}$ vitamin $A$ palmitate $\left(5000000 \mathrm{lU} / \mathrm{g}\right.$ ), $0.2 \mathrm{~g}$ vitamin $\mathrm{D}_{3}$ (cholecalciferol, $5000000 \mathrm{IU} / \mathrm{g}$ ), $0.075 \mathrm{~g}$ vitamin $\mathrm{K}$ (phylloquinone) and $974.705 \mathrm{~g}$ sucrose.

$\S$ Antioxidant.

|| From total oil, CLA isomers are present in TAG form containing an 80:20 isomer ratio of cis- 9 , trans -11 and trans-10, cis-12, respectively. The remaining $10 \%$ of oil is composed of oleic acid (0.7\%), SFA (5.6\%) and other CLA isomers (3.7\%).

The $1 \%$ CLA diet in suckling animals corresponded to a daily administration of $1.5 \mathrm{mg}$ CLA oil provided/g rat from day 1 to 21. Low-capacity syringes (Hamilton Bonaduz AG, Bonaduz, Switzerland) adapted to oral twenty-five-gauge or twenty-three-gauge gavage tubes, $27 \mathrm{~mm}$ in length (ASICO, Westment, IL, USA) were used for oral administration before and after day 5, respectively. To allow gastric emptying, litters were separated from dams $1 \mathrm{~h}$ before oral supplementation.

\section{Collection and processing of dam milk}

Milk was collected from dams on day 21 post-partum. Pups were separated from dams $1 \mathrm{~h}$ before milk extraction to allow the milk to accumulate in the mammary glands. Then females were anaesthetised intramusculary (i.m) with ketamine $(90 \mathrm{mg} / \mathrm{kg}$ rat) and then treated i.m with 2 IU oxytocin (Novartis, Barcelona, Spain) $10 \mathrm{~min}$ before milking. By gentle hand stripping of teats, milk droplets were collected into a test-tube using silastic tubing connected to a gentle suction. Total milk was used for CLA quantification, whereas Ig determination was performed in milk whey supernatant fractions after centrifugation $\left(600 \mathrm{~g}, 30 \mathrm{~min}, 4^{\circ} \mathrm{C}\right)$ and fat layer discarding.
Quantification of conjugated linoleic acid isomers in pup plasma and in dam milk

The content of $c 9, t 11-$ and $t 10, c 12-C L A$ isomers in the plasma of pups and fatty acid composition in the milk of dams were quantified by fast GC using a capillary column $(40 \mathrm{~m} \times 0.18 \mathrm{~mm} \times 0.20 \mu \mathrm{m})$, coated with RTX-2330 nonbonded stationary phase (poly $90 \%$ biscyanopropyl-10\% cyanopropylphenyl) siloxane from Thames Restek UK (High Wycombe, Bucks, UK) as previously described ${ }^{(30)}$. The identities of sample methyl ester peaks were determined by comparison of their relative retention times with those of well-known fatty acid methyl ester standards. Quantification was based on the amount of the internal standard recovered. The fatty acid composition of dams' milk was also evaluated. The results were expressed in relative amounts (\% total fatty acids). The CLA isomer content was also evaluated in the $1 \%$ enriched diet after the manufacturing process.

\section{Isolation and culture of spleen cells}

Spleen cell suspensions were obtained by passing the tissue through a steel mesh (Cellector ${ }^{\mathrm{TM}}$; Bellco, Vertieb, Austria) in sterile conditions. Cells were then centrifuged and re-suspended in PBS. Erythrocytes were lysed by adding distilled water to the cell suspension, and tonicity was restored by adding PBS $10 \times$. Afterwards, cells were centrifuged, washed, and finally re-suspended in Roswell Park Memorial Institute (RPMI)-10\% fetal bovine serum containing 0.05 mm-2-mercaptoethanol (Merck, Darmstadt, Germany), streptomycin-penicillin (100 IU/ml; Sigma Chemical Co., St Louis, MO, USA) and $2 \mathrm{mm-L-glutamine} \mathrm{(Sigma).} \mathrm{Cell}$ viability was determined by double staining with acridine orange and ethidium bromide (Sigma). Cells were plated and cultured in different conditions according to the assay.

\section{Lymphocyte proliferation}

Spleen cells were cultured at $1 \times 10^{5}$ cells/100 $\mu$ in a ninetysix-well plate and stimulated with phorbol myristate acetate plus ionomycin both at $250 \mathrm{ng} / \mathrm{ml}$ (Sigma). Lymphocyte proliferation was determined by a modified ELISA technique using Cell Proliferation Biotrak ${ }^{\mathrm{TM}}$ (Amersham Biosciences, Munich, Germany) after $72 \mathrm{~h}$ incubation. This assay is based on the measurement of 5-bromo-2'-deoxyuridine incorporation into proliferating cells during DNA synthesis. Absorbance (Ab) values correlate directly to the amount of DNA synthesised and, therefore, to the number of proliferating cells in culture. The proliferation rate (\%) was expressed considering $100 \%$ for the reference diet group, as follows:

Proliferation rate $(\%)=(\mathrm{A} / \mathrm{B}) \times 100$, where :

$$
\begin{aligned}
A= & \left(\left(A b_{\text {stimulated cells }}\right.\right. \\
& \left.\left.-A b_{\text {non-stimulated cells }}\right) / A b_{\text {non-stimulated cells }}\right)_{C L A \text { diet }} ; \\
B= & \left(\left(A b_{\text {stimulated cells }}\right.\right. \\
& \left.\left.-A b_{\text {non-stimulated cells }}\right) / A b_{\text {non-stimulated cells }}\right)_{\text {standard diet }} .
\end{aligned}
$$

A parallel plate was cultured with the same samples and conditions to determine cell viability. 
In vitro cytokine production

Splenocytes were cultured at $3 \times 10^{6}$ cells/ml in a twentyfour-well flat-bottom plate (TPP, Trasadingen, Switzerland) and stimulated with phorbol myristate acetate plus ionomycin $(250 \mathrm{ng} / \mathrm{ml})$ for $24 \mathrm{~h}$. The concentrations of IL-2, interferon- $\gamma$, IL-4 and IL-10 in the supernatant fractions were quantified using rat ELISA sets from Biosource (Nivelles, Belgium) and BD Pharmingen (Erembodegem, Belgium), following the manufacturers' instructions.

\section{Splenocyte in vitro immunoglobulin production and immunoglobulin concentrations in serum and milk whey}

Concentrations of IgG and IgM secreted during $7 \mathrm{~d}$ by nonstimulated spleen cells and serum and milk IgA, IgM and IgG concentrations were quantified by ELISA. Briefly, ninety-six-well polystyrene plates (Nunc Maxisorp, Wiesbaden, Germany) were coated with anti-rat IgA, anti-rat IgM or anti-rat IgG monoclonal antibodies (mAbs; BD Pharmingen) at 2, 2.5 and $10 \mu \mathrm{g} / \mathrm{ml}$ in PBS, respectively (overnight in a humidified chamber). The remaining binding sites were then blocked with PBS-1\% bovine serum albumin during $1 \mathrm{~h}$ at room temperature. Plates were washed $(3 \times$ with PBS-0.05\% Tween-20 and once with PBS), and the supernatant fractions, milk whey, serum and standard Ig dilutions (BD Pharmingen) in PBS-Tween $1 \%$ bovine serum albumin were then added and incubated ( $3 \mathrm{~h}$; room temperature). Plates were washed again and incubated $(2 \mathrm{~h}$; room temperature) with biotinylated anti-rat $\operatorname{IgA}$ or IgM (BD Pharmingen) at 0.625 and $1 \mu \mathrm{g} / \mathrm{ml}$, respectively, Subsequently, extravidinperoxidase conjugate $(4 \mu \mathrm{g} / \mathrm{ml}$ in PBS-Tween $1 \%$ bovine serum albumin) was added to the plates for $30 \mathrm{~min}$ at room temperature. A purified peroxidase anti-rat Ig antibody (Sigma) was used for IgG detection. Ig were detected by the addition of the substrate solution ( $o$-phenylenediamine dihydrochloride plus $\mathrm{H}_{2} \mathrm{O}_{2}$ in $0.2 \mathrm{M}$-phosphate-0.1 M-citrate buffer, $\mathrm{pH}$ 5). The enzyme reaction was stopped with $\mathrm{H}_{2} \mathrm{SO}_{4}$ ( $3 \mathrm{~mol} / \mathrm{l}$ ) and $\mathrm{Ab}$ was measured at $492 \mathrm{~nm}$.

\section{Statistical analysis}

SPSS 14.0 (SPSS Inc., Chicago, IL, USA) was used for the statistical analysis. Conventional one-way ANOVA was performed considering the experimental group based on CLA supplementation as the independent variable. When CLA supplementation had a significant effect on the dependent variable, Bonferroni's and Scheffe's tests were applied. The content of Ig in rat milk whey was analysed by the Student's $t$ test. Significant differences were accepted at $P<0 \cdot 05$.

\section{Results}

\section{Body weight}

The body weight of dams and pups was monitored daily throughout the study. The pregnant dams' starting body weight at $7 \mathrm{~d}$ gestation was 227.4 (SEM 4.2) g. The $1 \%$ CLA diet did not modify the dams' body weight increase during the gestation period: dams fed the $1 \%$ CLA or standard diet gained similar weight up to day 21 of gestation (308.7 (SEM 8.4) and 309.2 (SEM 10.4) g, respectively). Moreover, from day 7 to 21 of gestation, dams from both dietary groups had similar chow intake (5.9 (SEM 0.3) g/100 g rat per $\mathrm{d}$ for the $1 \%$ CLA diet group; 5.5 (SEM 0.5) g/100 g rat per $\mathrm{d}$ for the standard diet group). To assess the effect of CLA supplementation during gestation, pups from dams in groups $\mathrm{A}$ and $\mathrm{B}$ were taken together and compared on the day of birth with pups from dams fed the standard diet (groups $\mathrm{C}$ and D). The weight but not BMI and Lee index of neonates from the CLA-supplemented dams $(5 \cdot 7$ (SEM 0.1) g, $0 \cdot 2(\operatorname{SEM} 0 \cdot 1) \mathrm{g} / \mathrm{cm}^{2}$, and $0 \cdot 3(\mathrm{SEM} 0 \cdot 1) \mathrm{g} / \mathrm{cm}$, respectively) was lower than that from neonates whose dams received the standard diet during gestation (6.7 (SEM 0.1) g, 0.2 (SEM 0.1) $\mathrm{g} / \mathrm{cm}^{2}$ and $0.4($ SEM 0.1$) \mathrm{g} / \mathrm{cm}$, respectively) $(P<0.05)$.

Despite the slight differences among groups during week 1 of life, CLA-supplemented animals exhibited a similar body weight pattern when compared with pups from group D throughout the suckling period (Fig. 2), and at the end of the suckling period (day 21), weight, BMI and Lee index were similar among the groups $\left(49.1\right.$ (SEM 0.6) g, $0.4($ SEM 0.1$) \mathrm{g} / \mathrm{cm}^{2}$ and 0.3 (SEM 0.1$) \mathrm{g} / \mathrm{cm}$, respectively). As we have described in other previous experimental nutrition designs investigating this early life period ${ }^{(3)}$, there were no deaths in any of the groups in the present study. Animals' behaviour and organ weight and appearance were recorded as markers of CLA side effects and there was no evidence of abnormality.

\section{Conjugated linoleic acid content and fatty acid composition of dam milk}

At the end of suckling (day 21), milk from dams fed the CLA diet during gestation and suckling showed higher concentrations of the $c 9, t 11$ - and $t 10, c 12-C L A$ isomers than rats fed the standard diet $(P<0 \cdot 001)$ (Table 2$)$. The proportion of these two isomers in milk, 86:14, varied from that supplemented to dams, 80:20. Moreover, the $n-6: n-3$ proportion

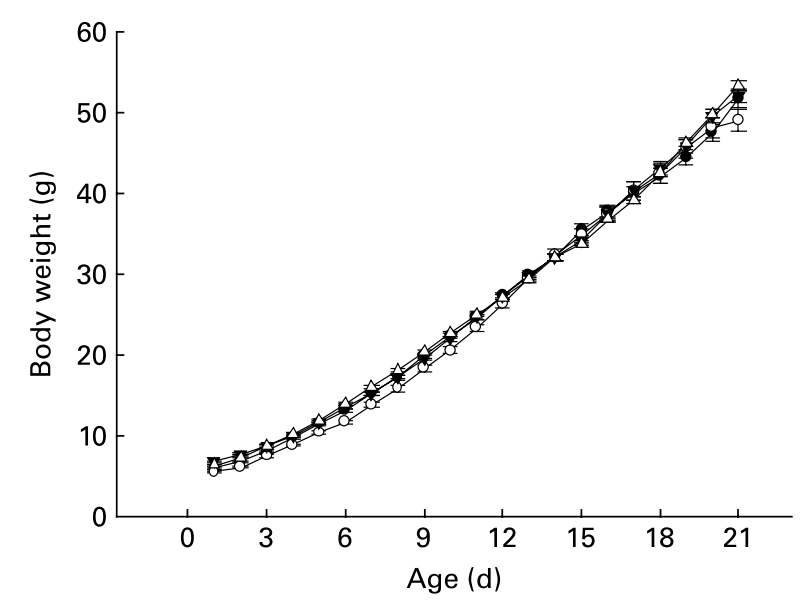

Fig. 2. Influence of conjugated linoleic acid (CLA) supplementation on body weight from day 1 to 21 . (--), Group A (CLA supplementation during gestation and suckling through dams (5 weeks)); (-O-), group B (CLA supplementation during gestation and suckling by oral administration ( 5 weeks)); $(-\boldsymbol{\nabla}-)$, group C (CLA supplementation during suckling by oral administration (3 weeks)); ( $\triangle-)$, group D (non-supplemented animals (0 weeks)). Values are means ( $n$ 15-20 pups per group), with standard errors represented by vertical bars. There were no significant differences among the groups based on a general linear model (ANOVA) with Bonferroni's adjustment for multiple comparisons. 
Table 2. Milk fatty acid composition of rats fed the standard or conjugated linoleic acid (CLA) diet ( $\mathrm{g} / 100 \mathrm{~g}$ total fatty acids) $\dagger$

(Mean values with their standard errors for four to seven dams per group)

\begin{tabular}{|c|c|c|c|c|}
\hline \multirow[b]{2}{*}{ Fatty acid } & \multicolumn{2}{|c|}{ Standard diet } & \multicolumn{2}{|c|}{ CLA diet } \\
\hline & Mean & SEM & Mean & SEM \\
\hline $8: 0$ & 1.67 & 0.02 & 1.62 & 0.04 \\
\hline $10: 0$ & $6 \cdot 31$ & 0.38 & 6.45 & $0 \cdot 10$ \\
\hline $11: 0$ & 0.06 & 0.01 & 0.06 & 0.00 \\
\hline $12: 0$ & $10 \cdot 14$ & 0.73 & $9 \cdot 89$ & 0.05 \\
\hline $14: 0$ & 11.97 & 0.36 & 11.51 & 0.12 \\
\hline $14: 1$ & 0.03 & 0.01 & 0.03 & 0.00 \\
\hline $15: 0$ & $0 \cdot 16$ & 0.01 & $0 \cdot 18^{*}$ & 0.00 \\
\hline $15: 1$ & 0.03 & 0.00 & $0.02^{*}$ & 0.00 \\
\hline $16: 0$ & $26 \cdot 37$ & 0.32 & $25 \cdot 16$ & 0.09 \\
\hline $16: 1$ & 1.47 & 0.01 & $1 \cdot 19^{*}$ & 0.01 \\
\hline $17: 0$ & 0.13 & 0.01 & $0 \cdot 12^{*}$ & 0.01 \\
\hline $17: 1$ & $0 \cdot 10$ & 0.01 & $0.09^{*}$ & 0.01 \\
\hline $18: 0$ & 3.29 & 0.16 & 3.54 & 0.04 \\
\hline $18: 1 n-9$ cis & $14 \cdot 29$ & 0.27 & $13 \cdot 80$ & 0.14 \\
\hline $18: 1 n-7$ & 0.75 & 0.02 & 0.77 & 0.01 \\
\hline $18: 2$ trans & 0.02 & 0.00 & $0 \cdot 01^{*}$ & 0.00 \\
\hline $18: 2 n-6$ cis & $17 \cdot 71$ & 0.59 & $16 \cdot 86$ & 0.49 \\
\hline $18: 3 n-6$ cis & 0.39 & 0.01 & $0.29^{*}$ & 0.01 \\
\hline $18: 3 n-3$ & $2 \cdot 12$ & 0.01 & $1.92^{*}$ & 0.03 \\
\hline $20: 0$ & 0.07 & 0.00 & $0.08^{*}$ & 0.01 \\
\hline Cis-9, trans-11-CLA & 0.02 & 0.00 & $2.93^{\star}$ & 0.11 \\
\hline $\begin{array}{l}\text { Cis-11, trans-13- and } \\
\text { trans-11, cis-13-CLA }\end{array}$ & 0.01 & 0.00 & $0 \cdot 12^{*}$ & 0.01 \\
\hline Trans-10, cis-12-CLA & 0.00 & 0.00 & $0.46^{*}$ & 0.02 \\
\hline $20: 1 n-9$ & 0.24 & 0.01 & $0.22^{*}$ & 0.01 \\
\hline Trans, trans-CLA & 0.02 & 0.00 & $0.24^{*}$ & 0.01 \\
\hline $20: 2 n-6$ & 0.40 & 0.00 & $0.23^{*}$ & 0.00 \\
\hline $20: 3 n-6$ & 0.39 & 0.01 & $0.38^{*}$ & 0.01 \\
\hline $20: 4 n-6$ & 0.95 & 0.01 & 0.96 & 0.02 \\
\hline $22: 0$ & 0.00 & 0.00 & 0.01 & 0.00 \\
\hline $22: 1$ & 0.03 & 0.01 & $0.02^{*}$ & 0.00 \\
\hline $22: 2$ & 0.23 & 0.01 & $0.21^{*}$ & 0.00 \\
\hline $20: 5 n-3$ & 0.03 & 0.00 & $0.04^{*}$ & 0.00 \\
\hline $22: 4 n-6$ & 0.16 & 0.01 & $0.13^{\star}$ & 0.01 \\
\hline $22: 5 n-6$ & 0.03 & 0.00 & $0.04^{*}$ & 0.00 \\
\hline $24: 0$ & 0.04 & 0.00 & 0.04 & 0.00 \\
\hline $24: 1$ & 0.01 & 0.00 & 0.01 & 0.00 \\
\hline $22: 5 n-3$ & 0.12 & 0.00 & 0.12 & 0.00 \\
\hline $22: 6 n-3$ & 0.22 & 0.00 & 0.22 & 0.01 \\
\hline
\end{tabular}

* Mean value was significantly different from that of the standard diet group $(P<0.001$; Student's $t$ test $)$.

†The composition of milk was evaluated on day 21 of suckling. present in the milk of dams fed CLA was 8.04, whereas it was 8.21 in milk from dams fed the standard diet. CLA induced changes in the fatty acid profile of milk from supplemented rats (Table 2).

\section{Conjugated linoleic acid content in pup plasma}

The concentration of CLA in the plasma of pups was determined on the day of weaning, following dietary supplementation either through gestation and suckling from the dam or by oral administration. Pups from group D showed a low plasma content of $c 9, t 11-$ CLA and no $t 10, c 12-C L A$. Groups $\mathrm{A}, \mathrm{B}$ and $\mathrm{C}$ had approximately nine, twelve and six times higher levels of $c 9, t 11-C L A$ than group $\mathrm{D}$, respectively $(P<0.05)$ (Table 3). Moreover, groups A and B (both receiving CLA for 5 weeks) had higher concentrations of both CLA isomers than group $\mathrm{C}$ (fed CLA for 3 weeks; $P<0.05$ ). Although the supplemented proportion to dams and pups of $c 9, t 11$ - and $t 10, c 12-C L A$ was $80: 20$, the CLA content of the plasma of pups did not show this proportion in any group. The proportion of CLA isomers was 86:14, 93:7 and 94:6 for groups A, B and C, respectively. Hence, group B presented a higher content of $c 9, t 11-C L A$, but a lower content of $t 10, c 12-$ CLA than group $\mathrm{A}(P<0 \cdot 05)$.

\section{Immunoglobulin concentration in milk whey}

Concentrations of $\operatorname{IgG}$, IgA and IgM were quantified in dams' milk whey at the end of the suckling period ( $21 \mathrm{~d}$ postpartum) (Fig. 3). The predominant Ig present in rat milk was $\mathrm{IgG}$ (about $280 \mu \mathrm{g} / \mathrm{ml}$ ), followed by $\operatorname{IgA}$ (about $30 \mu \mathrm{g} / \mathrm{ml}$ ) and finally IgM (about $5 \mu \mathrm{g} / \mathrm{ml}$ ). Dams fed the CLA diet during gestation and suckling increased the concentration of the main $\mathrm{Ig}$ isotypes in rat milk, IgG and $\operatorname{IgA}$, about 6- and 2-fold, respectively $(P<0 \cdot 05)$.

\section{Serum immunoglobulin concentration}

Serum $\operatorname{IgG}, \operatorname{IgM}$ and $\operatorname{IgA}$ concentrations were quantified in 21-d-old animals (Fig. 4). Animals from group D showed about $5 \mathrm{mg} \mathrm{IgG} / \mathrm{ml}$ (Fig. 4(a)), about $95 \mu \mathrm{g} \mathrm{IgM} / \mathrm{ml}$ (Fig. 4(b)) and about $2.7 \mu \mathrm{g} \mathrm{IgA/ml} \mathrm{(Fig.} \mathrm{4(c)).} \mathrm{CLA} \mathrm{sup-}$ plementation for 5 weeks, 2 weeks during gestation and 3 weeks during suckling through the dams' milk (group A), increased the total Ig serum concentration almost 4-fold,

Table 3. Relative content of cis-9, trans-11- and trans-10, cis-12-conjugated linoleic acid (CLA) isomers in the plasma of 21 -d-old pups (\% total fatty acids)*

(Mean values with their standard errors for ten pups per group)

\begin{tabular}{|c|c|c|c|c|c|c|c|c|}
\hline \multirow{2}{*}{$\begin{array}{l}\text { Groupt... } \\
\text { CLA isomer }\end{array}$} & \multicolumn{2}{|c|}{$A$} & \multicolumn{2}{|c|}{ B } & \multicolumn{2}{|c|}{$\mathrm{C}$} & \multicolumn{2}{|c|}{$\mathrm{D}$} \\
\hline & Mean & SEM & Mean & SEM & Mean & SEM & Mean & SEM \\
\hline Cis-9, trans-11-CLA & 1.34 & 0.01 & $1 \cdot 78$ & 0.05 & 0.90 & 0.01 & 0.15 & 0.01 \\
\hline Trans-10, cis-12-CLA & 0.21 & 0.01 & $0 \cdot 13$ & 0.01 & 0.05 & 0.00 & ND & \\
\hline
\end{tabular}

ND, non-detectable.

* The content of both CLA isomers in pups' plasma was significantly different among all groups $(P<0.001$; one-way ANOVA).

† Group A were pups supplemented with $1 \%$ CLA during gestation and suckling through dams (5 weeks). Group B were pups supplemented with $1 \%$ CLA during gestation through dams and during suckling by oral administration (5 weeks). Group C were pups supplemented with 1\% CLA only during suckling by oral administration (3 weeks). Group D were non-supplemented pups (0 weeks). 

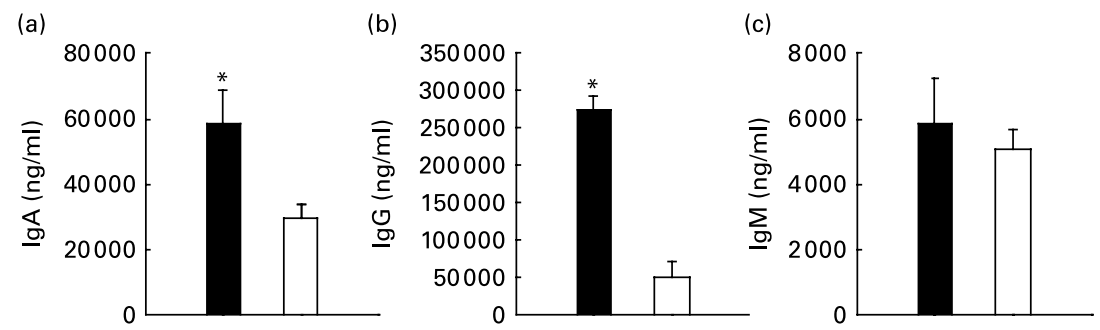

Fig. 3. Effects of conjugated linoleic acid (CLA) on IgA (a), IgG (b) and IgM (c) concentrations of rat milk collected on day 21 of the suckling period. ( $\square$ ), CLA diet; $(\square)$, standard diet. Values are means ( $n$ 4-7 dams per group), with standard errors represented by vertical bars. ${ }^{*}$ Mean value was significantly different from that of milk whey from dams fed the standard diet $(P<0.05$; Student's $t$ test).
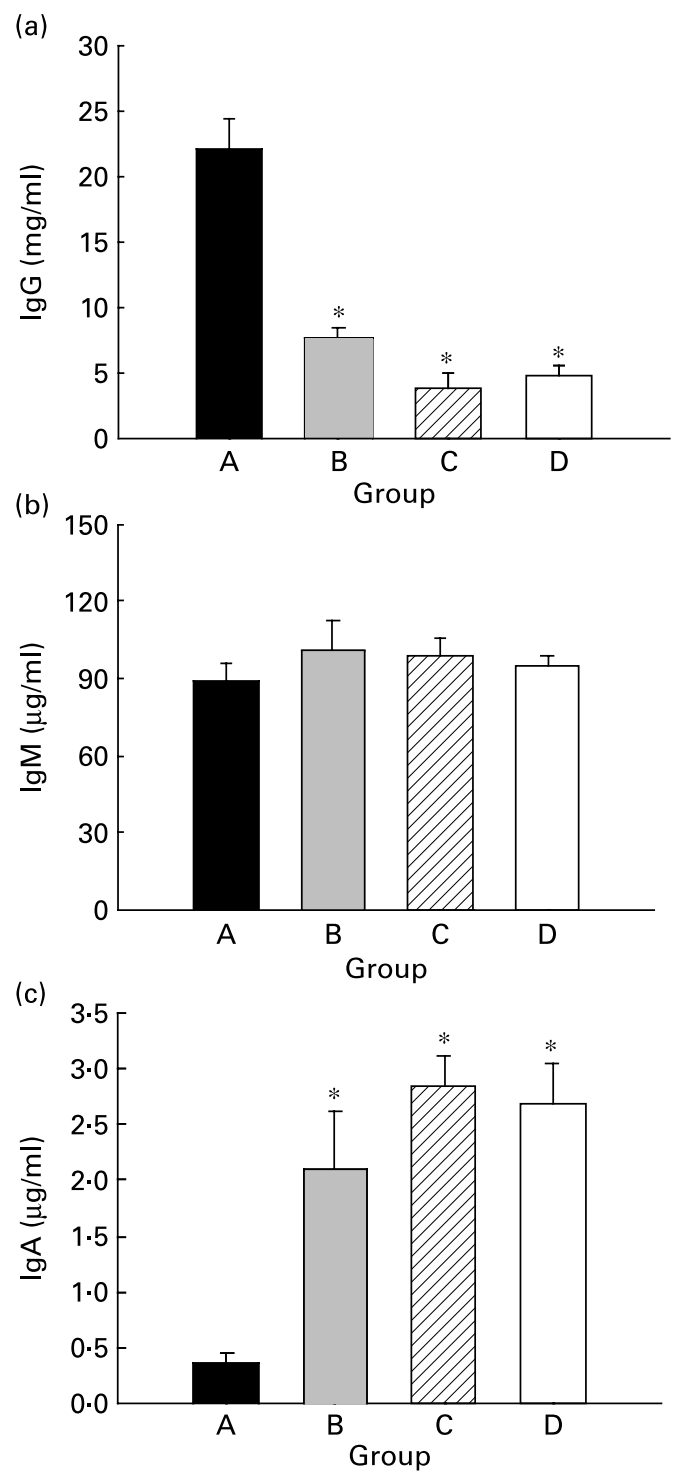

Fig. 4. Effects of conjugated linoleic acid (CLA) supplementation on serum $\lg G(a)$, IgM (b) and IgA (c) concentrations. Group A were pups supplemented with $1 \%$ CLA during gestation and suckling through dams ( 5 weeks). Group B were pups supplemented with $1 \%$ CLA during gestation through dams and during suckling by oral administration (5 weeks). Group C were pups supplemented with $1 \%$ CLA only during suckling by oral administration ( 3 weeks). Group D were non-supplemented pups (0 weeks). Values are means ( $n$ 15-20 pups per group), with standard errors represented by vertical bars. * Mean value was significantly different from that of group $A$ $(P<0.05$; one-way ANOVA). mainly by enhancement of IgG (Fig. 4(a)) $(P<0 \cdot 05)$. At this age, there were no differences in serum $\operatorname{IgM}$ concentration among the groups (Fig. 4(b)). However, group A exhibited a lower IgA serum concentration than those of the other groups (Fig. 4(c)) $(P<0 \cdot 05)$.

\section{Spleen lymphocyte proliferation, viability, and cytokine secretion}

The CLA diet did not modify the ex vivo lymphoproliferative capacity in any group, measured $72 \mathrm{~h}$ after phorbol myristate acetate plus ionomycin stimulation (Fig. 5(a)). To evaluate the effect of CLA and the relationship between proliferation and cell viability, we assessed splenocyte starting viability, which was about $95 \%$ for all groups, an optimum level for development of the assay. Cell viability was slightly reduced after phorbol myristate acetate plus ionomycin stimulation, but this decrease did not differ among groups, indicating that CLA dietary supplementation had no effect on splenocyte viability in 21-d-old animals. IL-2 production, the main proliferative signal for lymphocytes, was measured in supernatant fractions obtained after $24 \mathrm{~h}$ of spleen cell stimulation and was not modified by CLA supplementation (Table 4). Moreover, interferon- $\gamma$ was also secreted in similar amounts in all groups after mitogen stimulation. T helper 2 (Th2) cytokines, IL-4 and IL-10, were also quantified in the same splenocyte supernatant fractions and although no statistical differences were found among groups, due to the large intra-group variability, rats from groups A and B showed almost 2-fold higher values than those observed in groups C and D (Table 4).

\section{Splenocyte in vitro immunoglobulin production}

Spontaneous IgM and IgG production by splenocytes from weaning rats was quantified, and $\operatorname{IgM}$ was the main isotype found in supernatant fractions, being forty times higher than IgG $(P<0.05)$ (Fig. 6). Regarding CLA supplementation, IgM production from both groups supplemented for 5 weeks (groups A and B, about $900-1200 \mathrm{ng} / \mathrm{ml}$ ) was higher than that of the groups supplemented for 3 weeks (group C) and 0 weeks (group D) (both approximately, about $500 \mathrm{ng} / \mathrm{ml}$ ). However, this increase was only significant when pups received CLA during gestation and suckling by oral administration (group B) $(P<0.05)$ (Fig. 6(a)). Otherwise, IgG production was very low (about $10 \mathrm{ng} / \mathrm{ml}$ ) and no differences were found among groups (Fig. 6(b)). Thus, continuous CLA supplementation during gestation and suckling enhances 


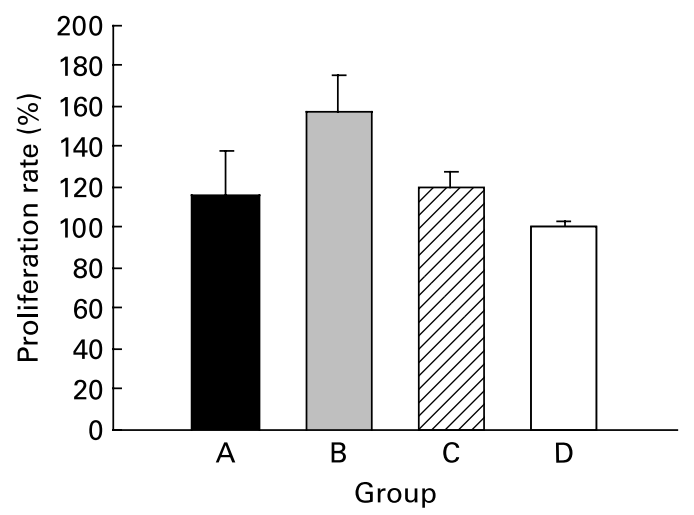

Fig. 5. Effects of conjugated linoleic acid (CLA) on proliferation rate in splenocytes stimulated with phorbol myristate acetate plus ionomycin. Group A were pups supplemented with $1 \%$ CLA during gestation and suckling through dams (5 weeks). Group B were pups supplemented with $1 \%$ CLA during gestation through dams and during suckling by oral administration (5 weeks). Group C were pups supplemented with $1 \%$ CLA only during suckling by oral administration (3 weeks). Group D were non-supplemented pups (0 weeks). Data are shown as percentage of controls (set at $100 \%$ ). Values are means ( $n$ 5-20 pups per group), with standard errors represented by vertical bars. CLA dietary supplementation did not modify splenocyte proliferation, regardless of period of supplementation or supplementation duration.

splenocyte IgM production, increasing total Ig concentration by almost two-fold that of non-supplemented animals.

\section{Discussion}

Evidence suggests that CLA has immunomodulatory properties $^{(19-22)}$, but there are no conclusive results in this regard either in animal or in human early life. We are not aware of any previous studies reporting the effects of CLA on immune function in suckling rats. Thus, this is the first study describing the influence of length (3,5 weeks), life period (gestation, suckling) and route of supplementation (placenta, breast milk, oral administration) on the immune effects of CLA.

Dietary supplementation with $1 \%$ of an 80:20 mix of $c 9, t 11$ - and $t 10, c 12-C L A$ isomers during gestation did not modify body weight or food intake of dams, in agreement with other studies of dams fed different CLA isomer mixtures during gestation and lactation ${ }^{(12,14,31)}$. Body weight on the day of birth was lower in pups from the CLA-fed dams than those from dams fed the standard diet. Thus, the effect of CLA supplementation during gestation was already evident on the delivery day, probably due to the body fat reduction effects of the $t 10, c 12$-CLA isomer ${ }^{(18,32)}$. Nevertheless, the effect of this isomer was not evidenced in older animals. This finding contrasts with results obtained in other species after feeding other CLA isomer mixtures ${ }^{(33,34)}$. Chin et al. ${ }^{(12)}$ reported a moderately enhanced body weight gain in rat pups after CLA administration during gestation and suckling. However, the present results are consistent with other studies that supplemented rats with a 50:50 isomer mixture during the same life period ${ }^{(14,31)}$. It is likely that these discrepancies are mainly due to differences in the isomers used in the related studies. Moreover, in the present study there were no negative side effects, as evidenced by the organs' weight and appearance, and the animals' behaviour. This is in keeping with CLA safety assessments carried out in animals $12,14,35,36)$ even when CLA comprised $5 \%$ of the $\operatorname{diet}^{(35)}$, and in human subjects consuming a maximum of $6 \mathrm{~g} / \mathrm{d}^{(37)}$. Moreover, evidence from studies using pure isomers has suggested that the adverse effects attributed to CLA may be due to the $t 10, c 12-C L A$ isomer ${ }^{(38)}$. In this sense, in the present study the rat CLA intake based on a consumption of $10 \mathrm{~g}$ of a $1 \%$ CLA diet per $100 \mathrm{~g}$ of rat per $\mathrm{d}$ is similar to the CLA doses used in human studies, which ranged from 0.7 to $6.8 \mathrm{~g} / \mathrm{d}^{(39)}$. However, the CLA intake of the rats in the present study is slightly higher than the average CLA intake of humans consuming occidental diets, which oscillates between $0 \cdot 3$ and $2 \cdot 6 \mathrm{~g} / \mathrm{d}^{(40)}$.

The results regarding the $c 9, t 11$ - and $t 10, c 12-C L A$ content in the plasma of all supplemented pups indicated that CLA was transferred from dams to pups during gestation and/or suckling. The plasma CLA content in the groups supplemented with the 80:20 CLA mix during gestation and suckling (groups A and B; 5 weeks) was about 1.5 and 2 times higher, respectively, than that of animals supplemented only during suckling (group C; 3 weeks). However, these results cannot demonstrate that CLA transfers through the placenta, since the plasma of newborns was not analysed. Nevertheless, Chin et al. ${ }^{(12)}$ found a 20 -fold increase of CLA in the liver of fetuses (at day 20 of gestation) from dams fed a $0.5 \%$ CLA

Table 4. Content of cytokines in $24 \mathrm{~h}$ splenocyte supernatant fractions stimulated with phorbol myristate acetate plus ionomycin $(250 \mathrm{ng} / \mathrm{ml})$

(Mean values with their standard errors for ten pups per group)

\begin{tabular}{|c|c|c|c|c|c|c|c|c|}
\hline \multirow{2}{*}{$\begin{array}{l}\text { Groupt... } \\
\text { Cytokines }\end{array}$} & \multicolumn{2}{|c|}{ A } & \multicolumn{2}{|c|}{ B } & \multicolumn{2}{|c|}{$\mathrm{C}$} & \multicolumn{2}{|c|}{ D } \\
\hline & Mean & SEM & Mean & SEM & Mean & SEM & Mean & SEM \\
\hline \multicolumn{9}{|l|}{ Th1 } \\
\hline IL-2 (ng/ml) & $4 \cdot 10$ & 1.04 & $4 \cdot 10$ & 1.01 & $5 \cdot 65$ & 0.93 & $4 \cdot 10$ & 0.79 \\
\hline Interferon- $\gamma(\mathrm{ng} / \mathrm{ml})$ & 4.61 & 0.79 & 5.93 & 1.02 & $6 \cdot 37$ & $1 \cdot 36$ & $3 \cdot 70$ & $0 \cdot 81$ \\
\hline \multicolumn{9}{|l|}{ Th2 } \\
\hline IL-2 (ng/ml) & $29 \cdot 32$ & $7 \cdot 97$ & $32 \cdot 43^{\star}$ & 5.99 & $15 \cdot 86$ & $1 \cdot 31$ & 12.44 & 1.82 \\
\hline Interferon- $\gamma(\mathrm{ng} / \mathrm{ml})$ & 181.68 & $47 \cdot 24$ & $176 \cdot 33$ & $43 \cdot 80$ & 90.59 & 8.53 & $108 \cdot 03$ & 19.62 \\
\hline
\end{tabular}

Th, T helper.

* Mean value was significantly different from that of group $D(P=0.06$; one-way ANOVA).

† Group A were pups supplemented with $1 \%$ CLA during gestation and suckling through dams (5 weeks). Group B were pups supplemented with $1 \%$ CLA during gestation through dams and during suckling by oral administration (5 weeks). Group $\mathrm{C}$ were pups supplemented with $1 \%$ CLA only during suckling by oral administration ( 3 weeks). Group D were non-supplemented pups ( 0 weeks). 

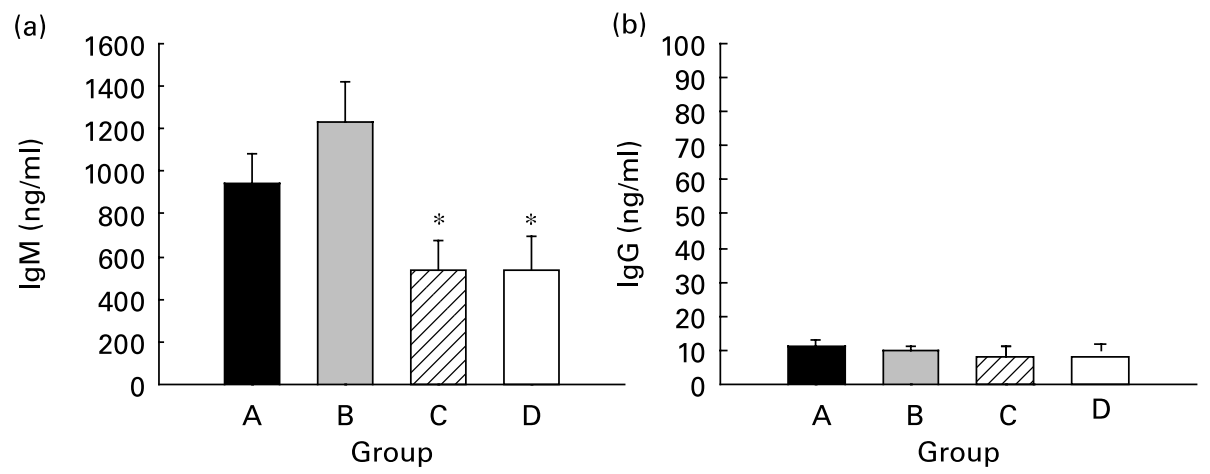

Fig. 6. Effects of conjugated linoleic acid (CLA) on spleen cell Ig secretion. $\operatorname{lgM}(\mathrm{a})$ and $\lg G(\mathrm{~b})$ concentrations in supernatant fractions after $7 \mathrm{~d}$ of spleen cell culture. Group A were pups supplemented with $1 \%$ CLA during gestation and suckling through dams (5 weeks). Group B were pups supplemented with $1 \%$ CLA during gestation through dams and during suckling by oral administration (5 weeks). Group C were pups supplemented with $1 \%$ CLA only during suckling by oral administration ( 3 weeks). Group D were non-supplemented pups ( 0 weeks). Values are means $(n 15-20$ pups per group), with standard errors represented by vertical bars. ${ }^{*}$ Mean value was significantly different from that of group B $(P<0.05$; one-way ANOVA).

diet during gestation than in fetal livers coming from dams fed a control diet. This, together with our findings of a higher content of $c 9, t 11$ - and $t 10, c 12$-CLA in the milk of rats fed CLA than in those fed the standard diet and the higher content of this isomer in group B plasma than in group C, confirms that CLA is transferred through the placenta to the fetus, as well as through the milk to the pup. The highest plasma CLA values in pups from group B may be due to CLA transfer during suckling from the maternal stores accumulated during gestation, besides supplementation by oral administration. Moreover, differences between groups A and B in the proportion of CLA isomers in pups' plasma may be due to the influence of the food matrix in group A, as milk is one of the major factors that affect PUFA bioavailability $^{(41)}$.

Despite the fact that an 80:20 isomer mix was used in all supplemented animals, the $c 9, t 11$ - and $t 10, c 12-C L A$ proportion was maintained neither in dams' milk (86:14), nor in pups' plasma (group A, 86:14; group B, 93:7; group C, 94:6). The lower proportion of $t 10, c 12-C L A$ than that initially supplemented is probably due to the faster metabolism of this isomer. It has been reported that $t 10, c 12$-CLA activates the $\beta$-oxidation system more strongly than $c 9, t 11$-CLA in rats; therefore, the former could easily become oxidised ${ }^{(42)}$. In addition, the immune effects of CLA seen in the present study occurred in the groups supplemented during gestation and suckling, perhaps because of incorporation of $c 9, t 11$ CLA to cell membranes and tissue since gestation, while no effects were observed when CLA supplementation was restricted to the suckling period. This might be explained by the fact that $c 9, t 11-$ CLA has been seen to accumulate to a greater extent than $t 10, c 12-C L A$ in tissue phospholipids of liver $^{(43)}$, skin and bone of experimental animals ${ }^{(44)}$. Interestingly, the CLA isomer proportion in pups' plasma from group A maintains the proportion found in dams' milk after consuming the CLA diet.

The presence of a small quantity of $c 9, t 11$ - and not of $t 10, c 12-C L A$ in the milk and plasma of non-supplemented rats supports the concept that rats produce rumenic acid ( $c 9, t 11-C L A)$, as has been suggested by other authors, by conversion of free linoleic acid by the intestinal bacterial flora $^{(45)}$ or by the endogenous conversion of trans-vaccenic acid, present in vegetable oils contained in standard diets ${ }^{(46)}$.
Rat milk not only transfers CLA to pups, but also antibodies, such as IgG, IgA and IgM. Dams fed the standard diet had a milk concentration pattern of $\operatorname{IgG}>\operatorname{IgA}>\operatorname{IgM}$, which agrees with that described by Dahlgren et al. ${ }^{(47)}$. This pattern was maintained in dams fed the CLA diet, although $\mathrm{IgG}$ and $\mathrm{IgA}$ concentrations were much higher in these rats. It has been described that $\operatorname{IgA}$ and $\mathrm{IgG}$ present in rat milk have a local mammary gland production ${ }^{(47)}$, which could be advantageous for rat pups since they absorb these Ig from the ingested milk through the intestinal mucosa and may extend beyond this compartment.

The present study also evaluated the effect of feeding an 80:20 CLA isomer mixture during gestation and suckling in the incipient antibody production of weaning rats. As rats can transmit Ig across the placenta, the rat neonatal model seems more appropriate to investigate the role of CLA on Ig production during pregnancy than the piglet model, due to the six-layered structure of the pig placenta which does not allow the transfer of $\mathrm{Ab}$ from the mother to the fetus ${ }^{(48)}$. Results in the rat model show the enhancing properties of CLA on the main in vivo serum Ig isotype, IgG. However, this effect was not observed in all the supplemented groups, a fact that underlines the importance of continuous CLA supplementation during gestation and suckling. This immuneenhancing effect has already been reported in older animals, as by Sugano et al. ${ }^{(49)}$ in 7 -week-old rats receiving $1 \%$ CLA (50:50 isomer mix), showing an increase in serum IgA, IgG and $\operatorname{IgM}$ concentrations and a decrease in $\operatorname{IgE}$. Song et al. ${ }^{(50)}$ reported a similar effect in human subjects following supplementation with a 50:50 isomer mixture for 12 weeks. Nevertheless, Yamasaki et al. ${ }^{(51)}$ found no significant effect on serum $\operatorname{IgA}, \operatorname{IgG}$ or $\operatorname{IgM}$ concentrations after feeding 5-week-old rats for 3 weeks with a 50:50 CLA isomer mixture at doses ranging from 0.05 to $0.5 \%{ }^{(51)}$. Discrepancies with the study reported by Yamasaki et al. ${ }^{(51)}$ might be due to the low doses of CLA tested in that study. Studies carried out in other species during gestation and lactation periods have also reported serum IgG increases ${ }^{(52,53)}$, in keeping with the present results.

With respect to the serum IgA decrease after CLA supplementation seen in the present study, Turpeinen et al. ${ }^{(54)}$ also detected an IgA reduction in subjects with birch pollen 
allergy supplemented for 12 weeks with a CLA mixture containing $63.5 \% \quad c 9, t 11$. Yamasaki et al. ${ }^{(51)}$ found a slightly lower concentration of serum $\operatorname{IgA}$ after feeding the $0.5 \%$ CLA dose, although the reduction was not significant. Considering that IgA is the main Ig in the gut surface (80-90\%) and the fact that systemic IgA-plasma cells continuously migrate to the intestinal wall ${ }^{(55)}$, the serum $\operatorname{IgA}$ decrease should not be interpreted as harmful. In fact, this serum IgA decrease is accompanied by an increase in intestinal IgA in CLA-supplemented weaned rats ${ }^{(56)}$. We also have reported an increase in mucosal IgA after a specific challenge in adult rats following this CLA diet through life ${ }^{(57)}$. Moreover, in the present study, CLA supplementation during gestation and suckling enhanced spleen IgM production. These results agree with other studies carried out in older rats, which reported enhancement of splenocyte Ig production after feeding 50:50 CLA isomer mixtures ${ }^{(49,51)}$. In addition, some authors have reported this increase in old mice after feeding the pure $t 10, c 12-C L A$ isomer ${ }^{(58)}$. Although the present results confirmed the immune-enhancing effect of the $c 9, t 11$ isomer, we cannot rule out immune functions for $t 10, c 12$-CLA.

In the present study, splenocyte proliferation rate and viability did not differ among the groups, partly due to the limited capacity of neonatal spleen lymphocytes to proliferate; at weaning this functional capacity is far less than that of adult rats ${ }^{(59)}$. Despite the present results, a wide range of PUFA, including CLA, have been found to reduce the mitogen-stimulated proliferation of lymphocytes isolated from several species ${ }^{(60,61)}$. A lack of effect of dietary CLA on lymphocyte proliferation has also been reported by Kelley et al. ${ }^{(19)}$ after feeding 8-week-old mice with pure isomers for $56 \mathrm{~d}$, and in human subjects either by ingestion of pure isomers ${ }^{(62)}$ or 50:50 and 80:20 isomer mixtures ${ }^{(19,63)}$. Since IL-2 plays a central role in the cell-mediated immune response by regulating proliferative abilities, it could be expected that if CLA does not modify splenocyte proliferation, it will not affect IL-2 production. The present results are consistent with most other studies in animals and human subjects, which have found no significant effects on IL-2 and interferon- $\gamma$ splenocyte secretion among the dietary groups $^{(58,62-64)}$. Nevertheless, some other studies have reported enhancement of IL-2 splenocyte production after CLA supplementation ${ }^{(65-67)}$. Once again, the assay conditions, particularly the isomer mixtures used, might hold the key to the differing impact of CLA in these studies. Although no significant effects were found on IL-4 and IL-10 splenocyte production, groups $\mathrm{A}$ and $\mathrm{B}$ exhibited a tendency towards higher values than groups $\mathrm{C}$ and $\mathrm{D}$. This IL-10 increase is in line with recent studies showing higher IL-10 production by dendritic cells incubated with $c 9$, $t 11$-CLA after stimulating with lipopolysaccharide ${ }^{(68)}$. This effect may be related to the anti-inflammatory properties attributed to $\mathrm{CLA}^{(26,69)}$. Moreover, by increasing IL-4, CLA might be promoting $\mathrm{T}$ helper 2 (Th2) responses, such as modulating antibody production and inhibiting several cellular functions, which is in agreement with the present results regarding CLA enhancement of the principal in vivo and in vitro Ig, whereas CLA did not modify splenocyte proliferation.

In summary, the present study is the first to investigate immune effects after supplementation with an 80:20 $c 9, t 11-t 10, c 12$ CLA isomer mixture during gestation and the entire suckling period. CLA supplementation increased milk $\operatorname{IgG}$ and $\operatorname{IgA}$ concentrations, serum IgG concentration and spleen IgM production. These effects were only observed in the CLA-supplemented groups from gestation on, and for the longer time period of 5 weeks, a fact that underscores the importance of this supplementation during gestation. Moreover, these data contribute to the scientific evidence pointing to the potential impact of lipid nutrition on immune system development during early life, particularly the effect of the $c 9, t 11-C L A$ isomer. To better delineate the importance of dietary supplementation during the early stages of life, further studies should focus on the effects of CLA mixtures in early suckling, when the immune system is even more immature, as well as in older weaning animals, when the immune system bears a high antigenic load with ingestion of the first solid diet.

\section{Acknowledgements}

The present study was supported in part by the Generalitat de Catalunya (SGCR-2005-00833). C. C. and A. F. acknowledge partial funding for this research from CIBER Epidemiología y Salud Pública (CIBERESP), Spain. C. R.-S. has a grant from the Spanish Agency for International Development Cooperation (Agencia Española de Cooperación Internacional; AECI). The oil used in the study was a gift from Loders Croklaan (Lipid Nutrition, Wormerveer, The Netherlands).

C. C., F. J. P.-C., M. R., M. R.-P. and A. F. designed the study and supervised the experimental work. C. R.-S., F. J. P.-C., C. C., M. C. and A. F. performed the experimental work. C. R.-S. and F. J. P.-C. analysed the data. C. R.-S. and F. J. P.-C. wrote the manuscript, with input from all authors. C. R.-S. and F. J. P.-C. contributed equally to the present study.

The authors have declared no conflict of interest.

\section{References}

1. Pérez-Cano FJ, Castellote C, González-Castro AM, et al. (2005) Developmental changes in intraepithelial $\mathrm{T}$ lymphocytes and NK cells in the small intestine of neonatal rats. Pediatr Res 58, 885-891.

2. Pérez-Cano FJ, Castellote C, Marín-Gallén S, et al. (2005) Neonatal immunoglobulin secretion and lymphocyte phenotype in rat small intestine lamina propria. Pediatr Res 58, 164-169.

3. Pérez-Cano FJ, Marín-Gallén S, Castell M, et al. (2007) Bovine whey protein concentrate supplementation modulates maturation of immune system in suckling rats. Br J Nutr 98, Suppl. 1, S80-S84.

4. Lönnerdal B (2003) Nutritional and physiologic significance of human milk proteins. Am J Clin Nutr 77, 1537S-1543S.

5. Field CJ (2005) The immunological components of human milk and their effect on immune development in infants. J Nutr 135, 1-4.

6. Kelly D \& Coutts AG (2000) Early nutrition and the development of immune function in the neonate. Proc Nutr Soc 59, 177-185.

7. Gil A \& Rueda R (2002) Interaction of early diet and the development of the immune system. Nutr Res Rev 15, 263-292. 
8. Field CJ, Clandinin MT \& Van Aerde JE (2001) Polyunsaturated fatty acids and T-cell function: implications for the neonate. Lipids 36, 1025-1032.

9. Mcguire MK, Park Y, Behre RA, et al. (1997) Conjugated linoleic acid concentrations of human milk and infant formula. Nutr Res 17, 1277-1283.

10. Jensen RG \& Lammi-Keefe C (2001) The anticarcinogenic conjugated fatty acid c9, t11-c18:2, or rumenic acid, in human milk: amounts and effects. Adv Exp Med Biol 501, 153-156.

11. Luna P, Juarez M \& Angel de la Fuente M (2007) Fatty acid and conjugated linoleic acid isomer profiles in human milk fat. Eur J Lipid Sci Technol 109, 1160-1166.

12. Chin SF, Storkson JM, Albright KJ, et al. (1994) Conjugated linoleic acid is a growth factor for rats as shown by enhanced weight gain and improved feed efficiency. J Nutr 124, 2344-2349.

13. Ha YL, Grimm NK \& Pariza MW (1987) Anticarcinogens from fried ground beef: heat-altered derivatives of linoleic acid. Carcinogenesis 8, 1881-1887.

14. Hayashi AA, de Medeiros SR, Carvalho MH, et al. (2007) Conjugated linoleic acid (CLA) effects on pups growth, milk composition and lipogenic enzymes in lactating rats. $J$ Dairy Res 74, 160-166.

15. Kelley NS, Hubbard NE \& Erickson KL (2007) Conjugated linoleic acid isomers and cancer. J Nutr 137, 2599-2607.

16. Nicolosi RJ, Rogers EJ, Kritchevsky D, et al. (1997) Dietary conjugated linoleic acid reduces plasma lipoproteins and early aortic atherosclerosis in hypercholesterolemic hamsters. Artery 22, 266-277.

17. Taylor CG \& Zahradka P (2004) Dietary conjugated linoleic acid and insulin sensitivity and resistance in rodent models. Am J Clin Nutr 79, Suppl., 1164S-1168S.

18. Park Y \& Pariza MW (2007) Mechanisms of body fat modulation by conjugated linoleic acid (CLA). Food Res Int 40, 311-323.

19. Kelley DS, Warren JM, Simon VA, et al. (2002) Similar effects of c9,t11-CLA and t10,c12-CLA on immune cell functions in mice. Lipids 37, 725-728.

20. O'Shea M, Bassaganya-Riera J \& Mohede IC (2004) Immunomodulatory properties of conjugated linoleic acid. Am J Clin Nutr 79, Suppl., 1199S-1206S.

21. Wahle KW, Heys SD \& Rotondo D (2004) Conjugated linoleic acids: are they beneficial or detrimental to health? Prog Lipid Res 43, 553-587.

22. Bhattacharya A, Banu J, Rahman M, et al. (2006) Biological effects of conjugated linoleic acids in health and disease. J Nutr Biochem 17, 789-810.

23. Pariza MW, Park Y \& Cook ME (2001) The biologically active isomers of conjugated linoleic acid. Prog Lipid Res 40, 283-298.

24. Storkson JM, Park Y, Cook ME, et al. (2005) Effects of trans-10, cis-12 conjugated linoleic acid (CLA) and cognates on apolipoprotein B secretion in HepG2 cells. Nutr Res 25, 387-389.

25. Moloney F, Toomey S, Noone E, et al. (2007) Antidiabetic effects of cis-9, trans-11-conjugated linoleic acid may be mediated via anti-inflammatory effects in white adipose tissue. Diabetes 56, 574-582.

26. Bassaganya-Riera J, Reynolds K, Martino-Catt S, et al. (2004) Activation of PPAR $\gamma$ and $\delta$ by conjugated linoleic acid mediates protection from experimental inflammatory bowel disease. Gastroenterology 127, 777-791.

27. Frazier AL, Ryan CT, Rockett H, et al. (2003) Adolescent diet and risk of breast cancer. Breast Cancer Res 5, R59-R64.

28. Novelli EL, Diniz YS, Galhardi CM, et al. (2007) Anthropometrical parameters and markers of obesity in rats. Lab Anim 41, 111-119.

29. Reeves PG, Nielsen FH \& Fahey GC Jr (1993) AIN-93 purified diets for laboratory rodents: final report of the American
Institute of Nutrition ad hoc writing committee on the reformulation of the AIN-76A rodent diet. J Nutr 123, 1939-1951.

30. Bondía-Pons I, Moltó-Puigmartí C, Castellote AI, et al. (2007) Determination of conjugated linoleic acid in human plasma by fast gas chromatography. J Chromatogr A 1157, 422-429.

31. Ringseis R, Saal D, Muller A, et al. (2004) Dietary conjugated linoleic acids lower the triacylglycerol concentration in the milk of lactating rats and impair the growth and increase the mortality of their suckling pups. J Nutr 134, 3327-3334.

32. Terpstra AH (2004) Effect of conjugated linoleic acid on body composition and plasma lipids in humans: an overview of the literature. Am J Clin Nutr 79, 352-361.

33. Poulos SP, Sisk M, Hausman DB, et al. (2001) Pre- and postnatal dietary conjugated linoleic acid alters adipose development, body weight gain and body composition in Sprague-Dawley rats. J Nutr 131, 2722-2731.

34. Schmid A, Collomb M, Bee G, et al. (2008) Effect of dietary alpine butter rich in conjugated linoleic acid on milk fat composition of lactating sows. Br J Nutr 100, 54-60.

35. Scimeca JA (1998) Toxicological evaluation of dietary conjugated linoleic acid in male Fischer 344 rats. Food Chem Toxicol 36, 391-395.

36. Park Y, Albright KJ \& Pariza MW (2005) Effects of conjugated linoleic acid on long term feeding in Fischer 344 rats. Food Chem Toxicol 43, 1273-1279.

37. Pariza MW (2004) Perspective on the safety and effectiveness of conjugated linoleic acid. Am J Clin Nutr 79, Suppl., 1132S-1136S.

38. Yamasaki M, Nishida E, Nou S, et al. (2005) Cytotoxity of the trans 10 , cis 12 isomer of conjugated linoleic acid on rat hepatoma and its modulation by other fatty acids, tocopherol, and tocotrienol. In Vitro Cell Dev Biol Anim 41, 239-244.

39. Tricon S, Burdge GC, Williams CM, et al. (2005) The effects of conjugated linoleic acid on human health-related outcomes. Proc Nutr Soc 64, 171-182.

40. Gómez-Candela C (2004) El papel del CLA o ácido linoleico conjugado sobre la masa grasa corporal (The role of CLA or conjugated linoleic acid on body fat mass). Nutr Diet 1, 75-83.

41. Schram LB, Nielsen CJ, Porsgaard T, et al. (2007) Food matrices affect the bioavailability of $(n-3)$ polyunsaturated fatty acids in a single meal study in humans. Food Res Int 40, 1062-1068.

42. Bowen RAR \& Clandinin MT (2005) Maternal dietary $22: 6 n-3$ is more effective than $18: 3 n-3$ in increasing the $22: 6 n-3$ content in phospholipids of glial cells from neonatal rat brain. Br J Nutr 93, 601-611.

43. Macarulla MT, Fernandez-Quintela A, Zabala A, et al. (2005) Effects of conjugated linoleic acid on liver composition and fatty acid oxidation are isomer-dependent in hamster. Nutrition 21, 512-519.

44. Kavanaugh CJ, Liu KL \& Belury MA (1999) Effect of dietary conjugated linoleic acid on phorbol ester-induced PGE2 production and hyperplasia in mouse epidermis. Nutr Cancer 33, $132-138$

45. Chin SF, Storkson JM, Liu W, et al. (1994) Conjugated linoleic acid (9,11- and 10,12-octadecadienoic acid) is produced in conventional but not germ-free rats fed linoleic acid. J Nutr 124, 694-701.

46. Santora JE, Palmquist DL \& Roehrig KL (2000) Trans-vaccenic acid is desaturated to conjugated linoleic acid in mice. $J$ Nutr 130, 208-215.

47. Dahlgren UI, Ahlstedt S \& Hanson LA (1986) Origin and kinetics of $\operatorname{IgA}, \mathrm{IgG}$ and $\mathrm{IgM}$ milk antibodies in primary and secondary responses of rats. Scand J Immunol 23, 273-278.

48. Redman DR (1979) Prenatal influence of immunocompetence of the neonate. J Anim Sci 49, 258-267.

49. Sugano M, Tsujita A, Yamasaki M, et al. (1998) Conjugated linoleic acid modulates tissue levels of chemical mediators and immunoglobulins in rats. Lipids 33, 521-527. 
50. Song HJ, Grant I, Rotondo D, et al. (2005) Effect of CLA supplementation on immune function in young healthy volunteers. Eur J Clin Nutr 59, 508-517.

51. Yamasaki M, Kishihara K, Mansho K, et al. (2000) Dietary conjugated linoleic acid increases immunoglobulin productivity of Sprague-Dawley rat spleen lymphocytes. Biosci Biotechnol Biochem 64, 2159-2164.

52. Bontempo V, Sciannimanico D, Pastorelli G, et al. (2004) Dietary conjugated linoleic acid positively affects immunologic variables in lactating sows and piglets. $J$ Nutr 134, 817-824.

53. Rossi R, Pastorelli G, Bontempo V, et al. (2004) Effects of dietary conjugated linoleic acid (CLA) on immunoglobulin concentration in sow colostrum and piglet serum. Vet Res Commun $\mathbf{2 8}$, Suppl. 1, 241-244.

54. Turpeinen AM, Ylonen N, von Willebrand E, et al. (2008) Immunological and metabolic effects of cis-9, trans-11-conjugated linoleic acid in subjects with birch pollen allergy. $\mathrm{Br} J$ Nutr 100, 112-119.

55. Brandtzaeg P \& Johansen FE (2005) Mucosal B cells: phenotypic characteristics, transcriptional regulation, and homing properties. Immunol Rev 206, 32-63.

56. Pérez-Cano FJ, Ramírez-Santana C, Molero-Luís M, et al. (2009) Mucosal IgA increase in rats by continuous CLA feeding during suckling and early infancy. J Lipid Res 50, 467-476.

57. Ramirez-Santana C, Castellote C, Castell M, et al. (2009) Longterm feeding of the cis-9,trans-11 isomer of conjugated linoleic acid reinforces the specific immune response in rats. J Nutr $\mathbf{1 3 9}$, $76-81$.

58. Yamasaki M, Chujo H, Hirao A, et al. (2003) Immunoglobulin and cytokine production from spleen lymphocytes is modulated in C57BL/6J mice by dietary cis-9, trans-11 and trans-10, cis-12 conjugated linoleic acid. J Nutr 133, 784-788.

59. Pérez-Cano FJ, Castellote C, Marín-Gallén S, et al. (2007) Phenotypic and functional characteristics of rat spleen lymphocytes during suckling. Dev Comp Immunol 31, 1264-1277.
60. Calder PC, Yaqoob P, Thies F, et al. (2002) Fatty acids and lymphocyte functions. Br J Nutr 87, Suppl. 1, S31-S48.

61. Nunes EA, Bonatto SJ, de Oliveira HH, et al. (2008) The effect of dietary supplementation with 9-cis:12-trans and 10-trans: 12-cis conjugated linoleic acid (CLA) for nine months on serum cholesterol, lymphocyte proliferation and polymorphonuclear cells function in Beagle dogs. Res Vet Sci 84, 62-67.

62. Tricon S, Burdge GC, Kew S, et al. (2004) Effects of cis-9, trans11 and trans-10,cis-12 conjugated linoleic acid on immune cell function in healthy humans. Am J Clin Nutr 80, 1626-1633.

63. Albers R, van der Wielen RP, Brink EJ, et al. (2003) Effects of cis-9, trans-11 and trans-10, cis-12 conjugated linoleic acid (CLA) isomers on immune function in healthy men. Eur $J$ Clin Nutr 57, 595-603.

64. Kelley DS \& Erickson KL (2003) Modulation of body composition and immune cell functions by conjugated linoleic acid in humans and animal models: benefits vs. risks. Lipids 38, 377-386.

65. Yang M \& Cook ME (2002) Dietary conjugated linoleic acid decreased cachexia, macrophage tumor necrosis factor- $\alpha$ production, and modifies splenocyte cytokines production. Exp Biol Med 228, 51-58.

66. Hayek MG, Han SN, Wu D, et al. (1999) Dietary conjugated linoleic acid influences the immune response of young and old C57BL/6NCrlBR mice. J Nutr 129, 32-38.

67. Turpeinen AM, von Willebrand E, Salminen I, et al. (2006) Effects of cis-9,trans-11 CLA in rats at intake levels reported for breast-fed infants. Lipids 41, 669-677.

68. Loscher CE, Draper E, Leavy O, et al. (2005) Conjugated linoleic acid suppresses NF- $\kappa \mathrm{B}$ activation and IL-12 production in dendritic cells through ERK-mediated IL-10 induction. J Immunol 175, 4990-4998.

69. Bergamo P, Maurano F, D'Arienzo R, et al. (2008) Association between activation of phase 2 enzymes and down-regulation of dendritic cell maturation by c9,t11-conjugated linoleic acid. Immunol Lett 117, 181-190. 